\title{
APLIKASI WEB SERVICE APTIMAS DENGAN ARSITEKTUR REPRESENTATIONAL STATE TRANSFER (REST) API
}

\author{
Supono $^{1}$, Sari Armiati \\ Prodi D3 Manajemen Informatika, Politenkin Pos Indonesia ${ }^{1}$ \\ Email : supono@poltekpos.ac.id ${ }^{1}$ \\ rodi D3 Manajemen Informatika, Politenkin Pos Indonesia ${ }^{2}$ \\ Email : sariarmiati@poltekpos.ac.id ${ }^{2}$
}

\begin{abstract}
Abstrak
Saat ini data merupakan bagian yang penting di era transformasi teknologi informasi, proses komunikasi pun tidak dibatasi oleh perbedaan jenis perangkat yang digunakan membuat informasi dapat diakses degan mudah. Saat ini Lembaga Penelitian dan Pengabdian kepada Masyarakat (LPPM) Politeknik Pos Indonesia sudah memiliki pangkalan data dalam proses pengelolaan data penelitian, pengabdian, publikasi dan HaKI berbasis web. Saat ini akses data penelitian dan pengabdian masih terpusat di satu aplikasi dan tidak bisa diakses dengan menggunakan aplikasi selain aplikasi APTIMAS (Aplikasi Penelitian dan Pengabdian kepada Masyarakat). Tujuan penelitian ini adalah membuat aplikasi middle ware atau web service yang memberikan solusi agar aplikasi lain dapat mengkases data APTIMAS untuk berbagai keperluan, seperti untuk mobile apps, dashboard di aplikasi lain, dan kebutuhan data lainnya. Metode yang digunakan pada penelitian ini dimulai dengan melakukan analisis yang sedang berjalan, melakukan perancangan, implementasi, dan pengujian. Hasil penelitian ini adalah aplikasi Web Service dengan arsitektur Representational State Transfer (REST) Application Programming Interface (API) menggunakan bahasa pemrograman PHP dengan Framework Codeigniter dan database MySQL yang berfungsi untuk menjembatani dalam memberikan layanan untuk komunikasi data antar satu aplikasi dengan aplikasi lain.
\end{abstract}

Kata Kunci: Web Services, APTIMAS, REST, API.

\begin{abstract}
Now data is an important part in the era of information technology transformation, the communication process is not limited by the different types of devices used to make information easily accessible. Currently the Institute for Research and Community Service (LPPM) Pos Indonesia Polytechnic already has a database in the process of managing web-based research, service, publication and intellectual property data. Currently access to research and service data is still centralized in one application and cannot be accessed using applications other than the APTIMAS application (Research and Community Service Application). The purpose of this research is to create a middle ware application or web service that provides solutions so that other applications can access APTIMAS data for various purposes, such as for mobile apps, dashboards in other applications, and other data needs. The method used in this research begins with conducting ongoing analysis, designing, implementing, and testing. The result of this research is a Web Service application with a Representational State Transfer (REST) Application Programming Interface (API) architecture using the PHP programming language with the CodeIgniter Framework and MySQL database that serves to bridge the gap in providing services for data communication between one application and another.
\end{abstract}

Keywords: Web Services, APTIMAS, REST, API. 


\section{PENDAHULUAN}

Perkembangan teknologi dan informasi semakin pesat di era digital saat ini. Termasuk bagaimana informasi diolah dan didistribusikan ke pihak lain baik itu antar mesin atau langsung ke pengguna terakhir dalam hal ini penerima informasi (end user). Perguruan tinggi memiliki kebutuhan dalam pengelolaan dan pendistribusian data terkait dosen seperti data penelitian, pengabdian, publikasi, dan lainnya (Perkasa \& Setiawan, 2018). Undang-undang Republik Indonesia Nomor 12 Tahun 2012 tentang Pendidikan Tinggi dan Permenristekdikti Nomor 61 Tahun 2016 tentang Pangkalan Data Pendidikan Tinggi mengenai kewajiban perguruan tinggi untuk melaporkan data dan informasi penyelenggaran pendidikan tinggi secara benar dan tepat pada Pangkalan Data Pendidikan Tinggi (PDDIKTI) (Arifien \& Riastuti, 2019).

Politeknik Pos Indonesia saat ini sudah memiliki pangkalan data untuk kegiatan penelitian, pengabdian, publikasi dan Haki yaitu di aplikasi APTIMAS (Aplikasi Penelitian dan Pengabdian Kepada Masyarakat) yang diimplementasikan pada tahun 2019. Fitur aplikasi APTIMAS ini sudah dirasa cukup lengkap dari mulai kegiatan pengusulan penelitian atau pengabdian sampai dengan pelaporan akhir sudah terrekam di aplikasi, begitu juga untuk kegiatan publikasi dan Haki sudah lengkap dari mulai pengajuan, persetujuan dan tersimpan di APTIMAS (LPPM, 2019). Namun ada beberapa hal yang yang perlu dilakukan pengembangan, salah satunya adalah bagaimana data di APTIMAS tersebut dapat diambil oleh mesin atau aplikasi lain yang membutuhkan. Misalnya sebuah aplikasi dashboard dosen di luar APTIMAS membutuhkan data jumlah penelitian dosen yang bersangkutan, tetapi aplikasi dashboard tersebut tidak memiliki akses ke database APTIMAS, maka salah satu jalannya adalah membuatkan aplikasi penengah (middleware) yang dapat menjembatani kedua belah pihak agar dapat saling berkomunikasi (García \& Bellogín, 2018).

Pada penelitian sebelumnya tentang REST API untuk tema kegiatan penelitian dan pengabdian yang mengimpementasikan data penelitian dan pengabdian perguruan tinggi untuk tujuan mengambil data yang selanjutnya bertujuan untuk dimasukan ke pusat data Ristekdikti sebagai pangkalan data. Sehingga berbeda dengan penelitian yang peneliti implementasikan yang bertujuan untuk kepentingan pihak lain dalam pemanfaatan data penelitian dan pengabdian kepada masyarakat (Harjiono \& Susanto, 2020). Pada penelitian ini fokus pada bagaimana membuat sebuah aplikasi middleware atau dengan istilah lain adalah web service dengan Arsitektur Representational State Transfer (REST) Application Programming Interface (API) yang dapat dimanfaatkan oleh aplikasi lain untuk menjembatani dalam berkomunikasi pengambilan dan pengiriman data dari dan ke pangkalan data aplikasi APTIMAS dari aplikasi lain atau perangkat (aplikasi mobile) lain tanpa harus mengakses langsung database aplikasi APTIMAS.

Tujuan penelitian ini adalah adalah membuat aplikasi middleware dengan arsitektur Representational State Transfer (REST) Application Programming Interface (API) merupakan luaran penelitian ini yang dapat digunakan di lingkungan Politeknik Pos Indonesia, dan membuat dokumen perancangan dan pengembangan perangkat lunak dari aplikasi middleware ini.

\section{METODE PENELITIAN}

Metodologi yang akan digunakan dalam penelitian ini adalah kuantitatif dengan analisis deskriptif dan metode berbentuk eksperime. Tahapan yang akan ditempuh adalah sebagai berikut:

1. Tahap Persiapan

Pada tahap ini dilakukan kajian literatur mengenai alur kebutuhan data institusi dan pihak TIK (Teknologi Informasi Komunikasi) Politeknik Pos Indonesia yang berhubungan dengan data Penelitian dan Pengabdian (aplikasi APTIMAS). Usulan lokasi penelitian berada di Lembaga Penelitian dan Pengabdian kepada Masyarakat (LPPM) dan TIK Politeknik Pos Indonesia.

2. Tahap Analisis Kebutuhan

Pada tahapan ini dilakukan analisis kebutuhan-kebutuhan yang terdiri dari:

a. Kebutuhan pengguna

Berdasarkan hasil penelitian seperti tertera di dalam tinjauan pustaka, penelitian ini bertujuan memudahkan pada user yang terlibat dalam proses bisnis kebutuhan data apliikasi APTIMAS.

b. Kebutuhan fungsional aplikasi 
Berupa pendefinisian menu layanan, kegunaan yang harus disediakan oleh sistem serta penanganan oleh sistem pada kondisi khusus. Kemudian dipetakan data apa saja yang diperlukan dalam komunikasi data antara client dengan data server melalui REST API.

3. Tahap Perancangan

Sesuai analisis kebutuhan pengguna dan kebutuhan fungsional aplikasi, selanjutnya dilakukan perancangan sistem. Aktifitas yang akan dilakukan sebagai berikut:

a. Merancang arsitektur sistem.

b. Merancang pemodelan dengan menggunakan UML.

c. Merancang pengujian.

d. Merancang sistem data role

e. Merancang tampilan data dan antarmuka aplikasi.

4. Tahap Implementasi

Hasil perancangan sistem akan diimplementasikan kedalam bentuk aplikasi berbasis web menggunakan bahasa pemrograma PHP menggunakan framework Codeigniter dan database menggunakan MySQL. Selain itu dibuatkan dokumentasi yang baik dengan standar dokumentasi API.

5. Tahap Pengujian

Pada tahap ini akan dilakukan pengujian yang terdiri dari pengujian fungsional, pengujian fungsi, fitur dan penanganan kesalahan sesuai dengan rancangan sebelumnya. Pengujian penerimaan pengguna, pengujian aplikasi kepada semua, yang kemudian selanjutnya dilakukan evaluasi terhadap hasil pengujian sebelumnya.

Untuk pendekatan dan pemodelan sistem informasi, menggunakan pendekatan SDLC (Software Development Life Cycle) dengan jenis Prototiping yang memungkinkan sistem yang bekerja secara terus menerus diperbaiki melalui kerjasama antara user dan analis sistem (Fatta, 2017).

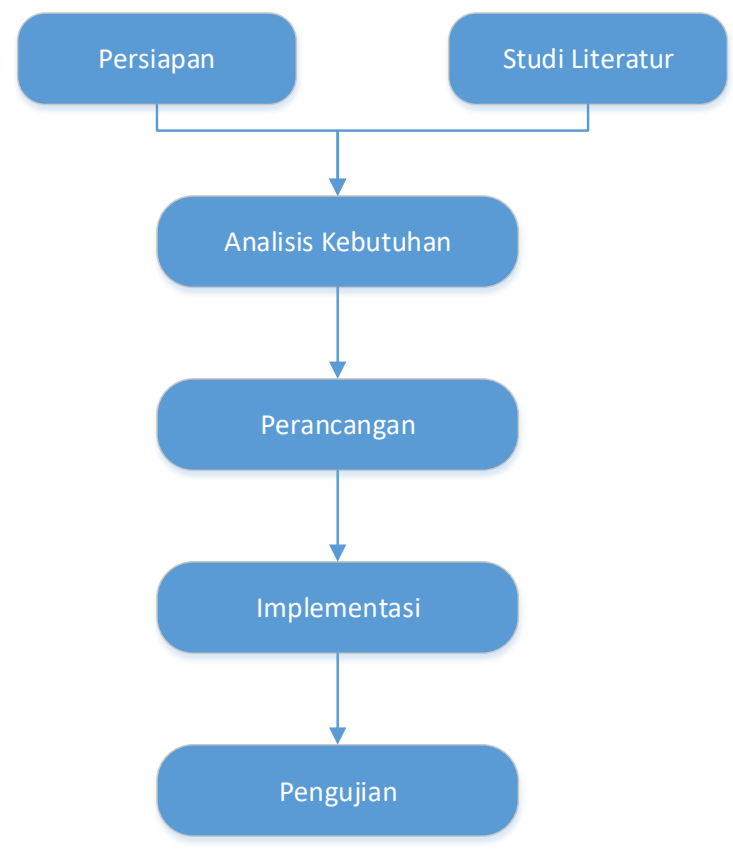

Gambar 1. Tahapan Penelitian

Pada tahapan diatas, menggambarkan alur dari penelitian yang dilakukan, dari mulai persiapan yang termasuk di dalamnya melakukan studi literatur dari penelitian-penelitian sebelumnya. Selanjutnya melakukan analisis kebutuhan berdasarkan kebutuhan pengguna dan secara fungsional. Selanjutnya melakukan perancangan, implementasi dan pengujian.

\section{HASIL DAN PEMBAHASAN}


Pada saat ini, aplikasi APTIMAS sudah berjalan dengan baik dan digunakan untuk keperluan kegiatan penelitian, pengabdian dan publikasi. Terdapat aplikasi lain yang mengakses data APTIMAS, yaitu aplikasi ITEUNG (IT Service Utility Integrated) dimana saat ini aplikasi tersebut langsung mengakses database APTIMAS tanpa melaului aplikasi perantara (middleware). Beberapa aplikasi lain tentu menginginkan data kegiatan penelitian, pengabdian dan publikasi untuk keperluan akreditasi dan dashboard di website nya unit masing-masing, salah satunya adalah Unit Program Studi.

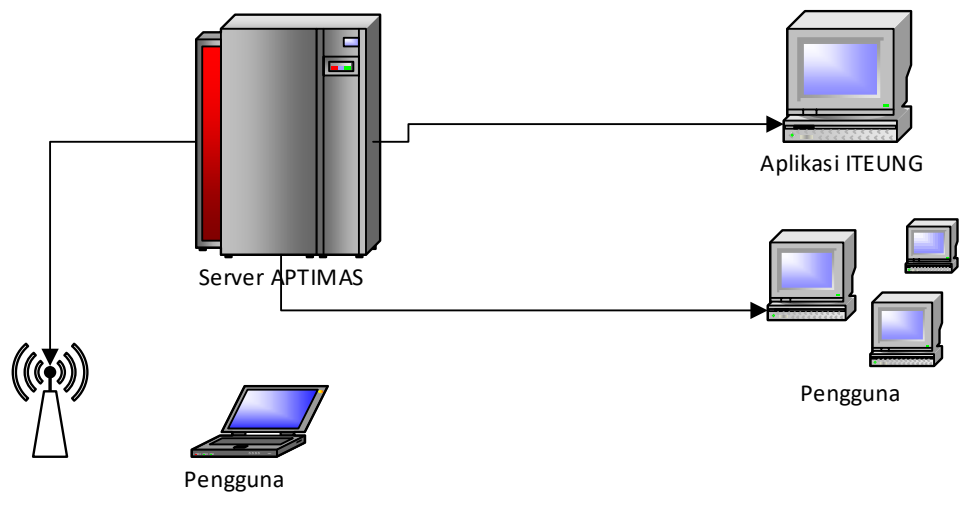

Gambar 2. Akses Data APTIMAS yang sedang berjalan

Pada gambar 2 di atas terlihat ada beberapa pengguna dan aplikasi yang mengakses data APTIMAS, saat ini yang mengakses data APTIMAS adalah dosen yang memiliki NIDN untuk kepentingan penelitian, pengabdian dan publikasi. Aplikasi iteung mengakses data APTIMAS dengan memanfaatkan fasilitas store procedure dalam bentuk view di database MySQL APTIMAS untuk mendapatkan data penelitian, pengabdian dan publikasi, kemudian data di olah lagi menggunakan bahasa pemrograman lain di aplikasi iteung.

Dari hasil pemodelan sistem yang sedang berjalan, terdapat beberapa permasalahan yang muncul, antara lain:

1. Akses data dari aplikasi lain ke pangkalan data APTIMAS langsung ke database dengan memanfaatkan Store Procedure dengan membuat view. Aplikasi memiliki akses penuh terhadap data yang ada di pangkalan data APTIMAS (memiliki username dan password database).

2. Tidak bisa digunakan oleh aplikasi luar yang tidak memiliki akses penuh terhadap pangkalan data APTIMAS. Aplikasi lain harus memiliki username dan password untuk dapat akses ke database.

3. Rentan terhadap keamanan data, karena setiap aplikasi bisa mengakses secara langsung data (DML/DDL) terhahadap data APTIMAS.

Untuk mengatasi hal di atas, maka dibangunlah sebuah aplikasi middleware sebagai jembatan antara aplikasi lain dengan data APTIMAS dimana tidak perlu memiliki akses username password database APTIMAS untuk mengaksesnya, hanya diperlukan sebuah token jika diperlukan itu juga. Aplikasi yang dibangun adalah Rancang Bangun Web Service Aptimas Dengan Arsitektur Representational State Transfer (REST) API berbasis web.

Adapun fitur-fitur yang diberikan oleh aplikasi REST API ini dimana aplikasi lain dapat mengambil data berdasarkan parameter atau URL yang di request ke server, selain itu terdapat dokumentasi penggunaan REST API di sisi client. Beberapa fitur yang dimaksud antara lain:

1. Menampilkan jumlah penelitian, pengabdian dan publikasi berdasarkan tahun.

2. Menampilkan data penelitian, pengabdian, publikasi dan HAKI berdasarkan program studi, berdasarkan dosen, dan tahun.

3. Menampilkan berdasarkan tahun, atau dosen atau program studi dengan parameter yang diberikan (pencarian data).

4. Untuk mengambil data, tidak diperlukan akses login, cukup menambhakan URL yang mengarah ke pangkalan data APTIMAS. 
Berikut ini rekomendasi sistem yang dirancang dan diimplementasikan sesuai dengan solusi atas permasalahan di atas dengan jugul Rancang Bangun Web Service Aptimas Dengan Arsitektur Representational State Transfer (REST) API.

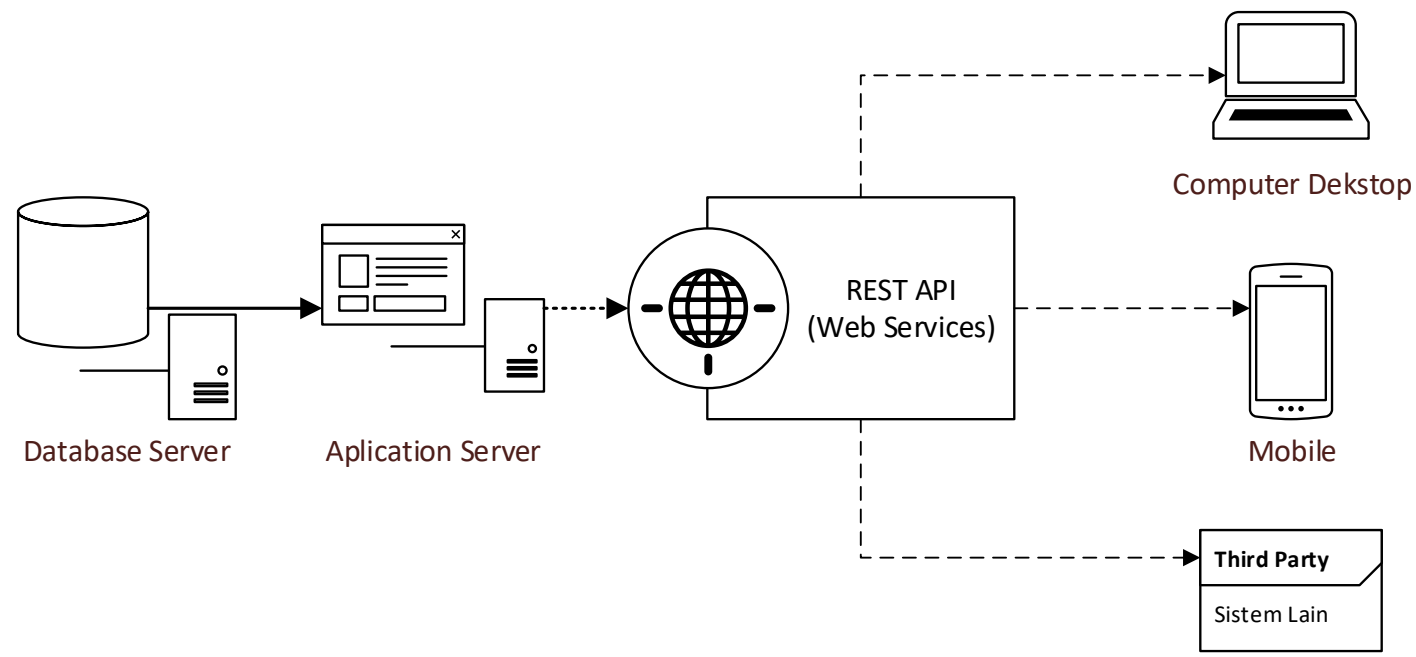

Gambar 3. Rekomendasi Akses Data APTIMAS Menggunakan REST API

Pada gambar 3 di atas direkomendasikan sebuah aplikasi dimana pihak atau aplikasi lain tidak langsung mengakses database server, melainkan harus melalui sebuah layer yang bernama REST API (Web Service) dimana dia melayani berbagai permintaan (request) yang sudah didefinisikan sebelumnya, seperti permintaan data penelitian berdasarkan dosen, program studi, tahun dan lainnya. Misalnya seseorang membangun sebuah aplikasi mobile dan menginginkan menampilkan informasi penelitian berdasarkan dosen yang bersangutan, maka dari aplikasi mobile tersebut tinggal mengirimkan URL dan parameter API ke aplikasi, kemudian aplikasi akan meneruskan ke Database Server untuk melakukan query sesuai dengan URL dan parameter yang diinginkan. Setelah itu, aplikasi akan mengembalikan data dengan format json ke aplikasi yang melakukan request, dan aplikasi yang melakukan request kemudian melakukan parsing data untuk menampilkan data agar mudah dibaca oleh end user atau pengguna terakhir.

Perancangan menggunakan class diagram sebagai berikut:

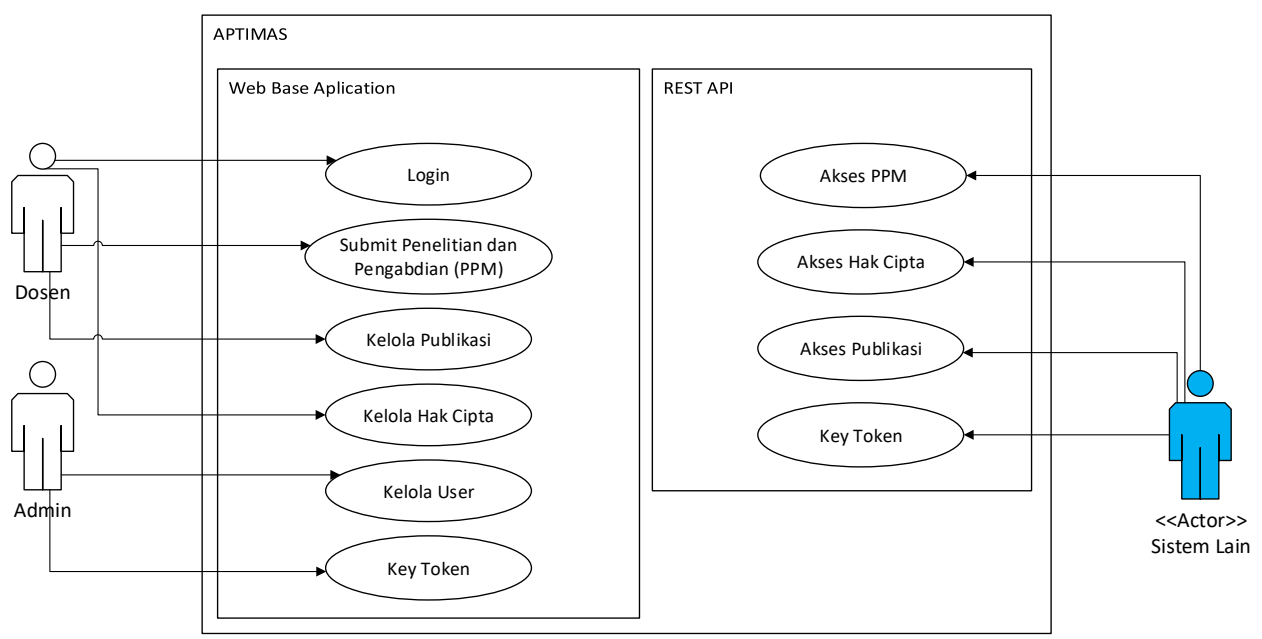

Gambar 4. Use Case Diagram 
Berikut ini implementasi REST API pada aplikasi POSTMAN sebagai masukan dan luaran untuk permintaan data beberapa parameter untuk penelitian, pengabdian kepada masyarakat, publikasi dan HAKI. Pada gambar 5 di dibawah aplikasi Postman mengirimkan data ke server POST API untuk melakukan permintaan data penelitian dengan mengirimkan sebuah parameter API-KEY untuk validasi data di server APTIMAS.

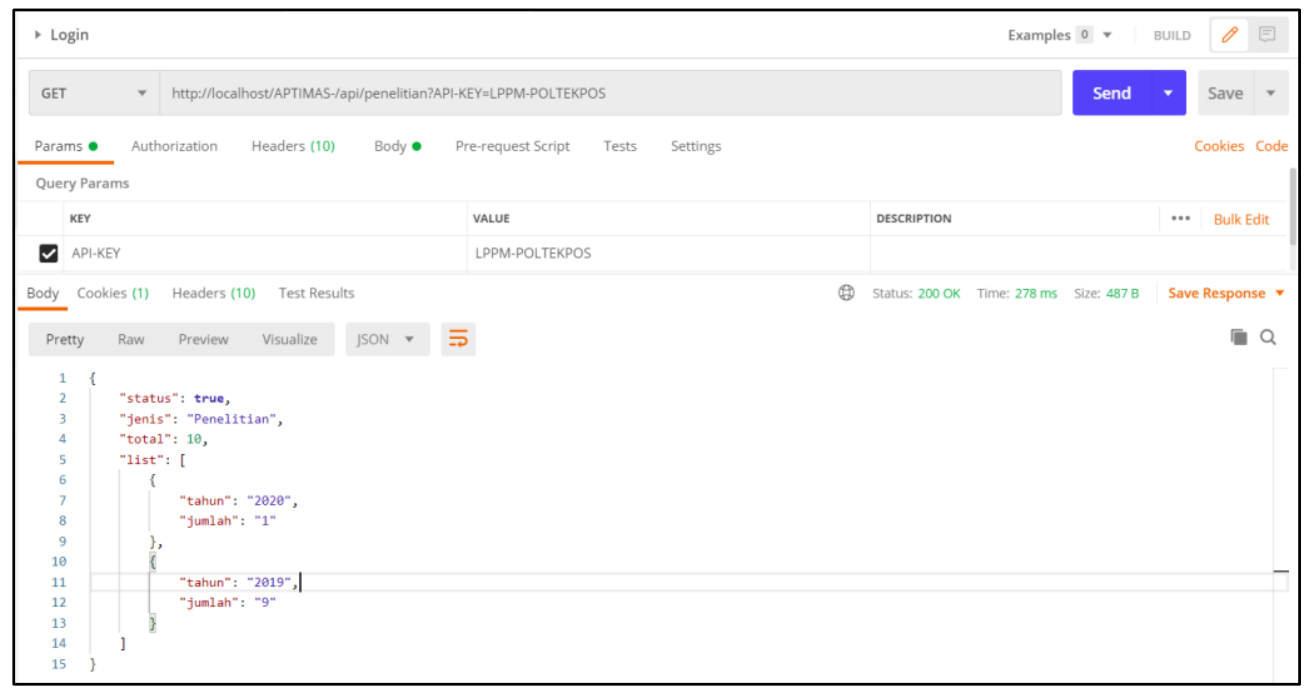

Gambar 5. Permintaan Data Melalui REST API

Berikut pengujian yang dilakukan untuk mengetahui sejauh mana aplikasi dapat berjalan dengan baik dan merespoan REST API.

1. Permintaan data berdasarkan tahun

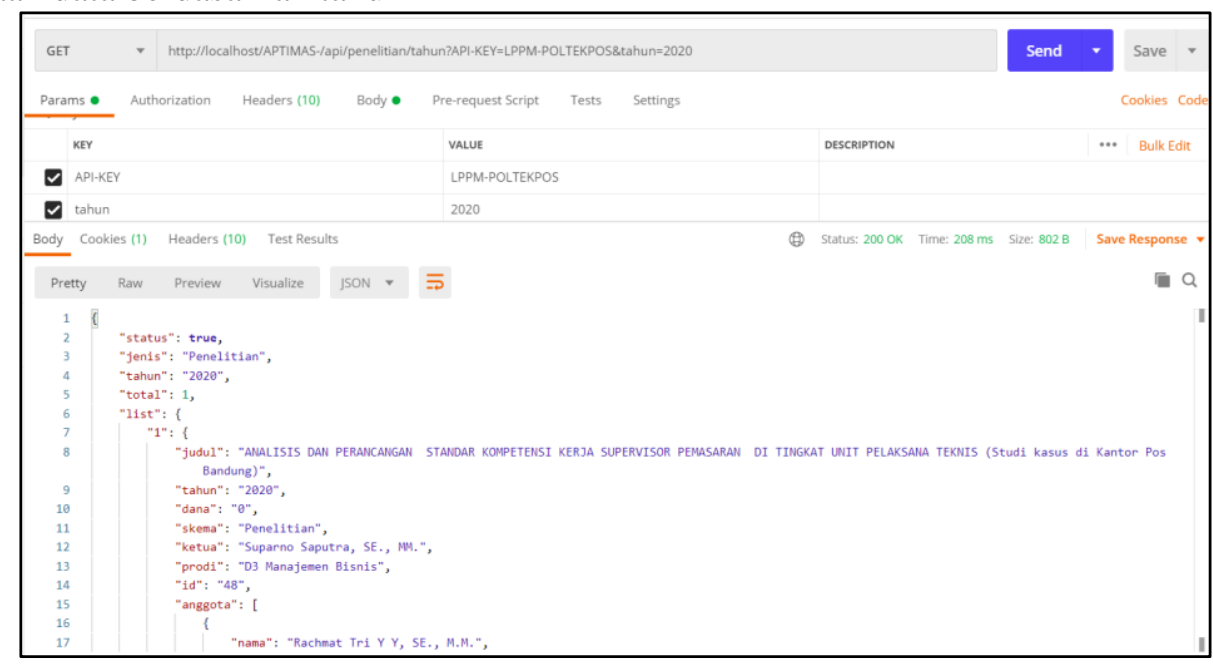

Gambar 6. Permintaan Data Melalui REST API

Menampilkan data jumlah penelitian pada tahun tersebut beserta data penelitiannya, seperti judul, skema, program studi, ketua peneliti dan anggota peneliti.

2. Permintaan Data Publikasi Berdasarkan Program Studi 


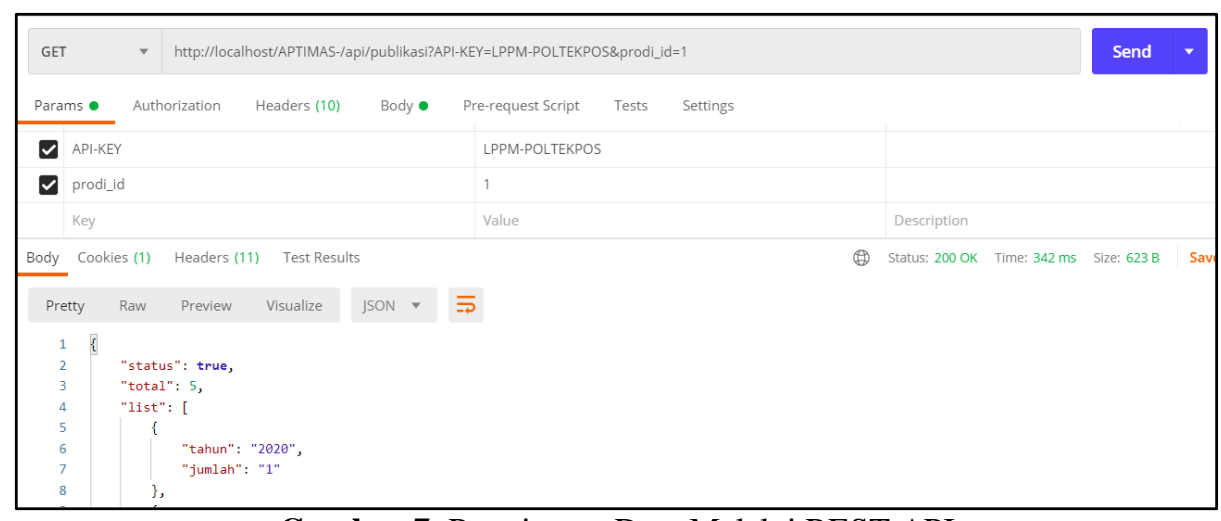

Gambar 7. Permintaan Data Melalui REST API

Pada bagian publikasi ini, permintaan data menampilkan data berdasarkan program studi yang menampilkan resume berdasarkan jumlah keseluruhan, tahun dan total jumlah publikasi pada tahun tersebut. Parameter yang dikirimkan adalah API-KEY dan prodi_id sesuai dengan data yang ada di APTIMAS

\section{KESIMPULAN}

Berdasarkan hasil penelitian yang dilakukan mulai dari melakukan analisis, perancangan sampai dengan implementasi, maka dapat disimpulkan sebagai berikut:

1. Telah dihasilkan perancangan dan implementasi sistem REST API APTIMAS server untuk permintaan data penelitian, pengabdian kepada masyarakat, publikasi dan HAKI dengan melakukan validasi berdasarkan KEY API pada aplikasi APTIMAS.

2. Telah dihasilkan REST API untuk sistem lain seperti aplikasi mobile yang dapat melakukan permintaan data berdasarkan parameter seperti berdasarkan tahun, program studi, dan dosen dalam hal ini NIDN.

\section{REFERENSI}

Arifien, F., \& Riastuti, M. (2019). Model Interoperabilitas Web Service Feeder PDDIKTI Menggunakan Enterprise Javabeans (EJB) dan REST-API. 3.

Armiati, S., \& Supono, S. (2020). APTIMAS (MODUL PENELITIAN DAN PENGABDIAN KEPADA MASYARAKAT). Jurnal SITECH, $3(1), \quad 1-8$. https://jurnal.umk.ac.id/index.php/sitech/article/view/4235

Fatta, H. Al. (2017). Pendekatan-Pendekatan Pengembangan Sistem.

García, I., \& Bellogín, A. (2018). Towards an open, collaborative REST API for recommender systems. RecSys 2018 - 12th ACM Conference on Recommender Systems, June, 504-505. https://doi.org/10.1145/3240323.3241615

Harjiono L.A, Susanto, L, W. (2020). Implementasi Web Service Integrasi Data Penelitian dan Pengabdian Masyarakat dengan SISTER Ristekdikti dengan Metode REST. Jurnal INFRA, 8 (2). http://publication.petra.ac.id/index.php/teknik-informatika/article/view/9995

LPPM. (2019). APTIMAS. Politeknik Pos Indonesia. https://aptimas.poltekpos.ac.id/

Masse, M. (2011). REST API Design Rulebook: Designing Consistent RESTful Web Service Interfaces. O'Reilly. https://books.google.de/books?id=eABpzyTcJNIC

Perkasa, M. I., \& Setiawan, E. B. (2018). Pembangunan Web Service Data Masyarakat Menggunakan REST API dengan Access Token. Jurnal ULTIMA Computing, 10(1), 19-26. https://doi.org/10.31937/sk.v10i1.838 
Polák, M., \& Holubová, I. (2015). Advanced REST API management and evolution using MDA. ACM International Conference Proceeding Series, 08-Septemb(1), 11-18. https://doi.org/10.1145/2881631.2881635 